\title{
Sensitivity to deliberate sea salt seeding of marine clouds - observations and model simulations
}

\author{
K. Alterskjær ${ }^{1}$, J. E. Kristjánsson ${ }^{1}$, and Ø. Seland ${ }^{2}$ \\ ${ }^{1}$ Department of Geosciences, Meteorology and Oceanography Section, University of Oslo, Oslo, Norway \\ ${ }^{2}$ Norwegian Meteorological Institute, Oslo, Norway \\ Correspondence to: K. Alterskjær (kari.alterskjar@geo.uio.no)
}

Received: 5 September 2011 - Published in Atmos. Chem. Phys. Discuss.: 31 October 2011

Revised: 28 February 2012 - Accepted: 1 March 2012 - Published: 15 March 2012

\begin{abstract}
Sea salt seeding of marine clouds to increase their albedo is a proposed technique to counteract or slow global warming. In this study, we first investigate the susceptibility of marine clouds to sea salt injections, using observational data of cloud droplet number concentration, cloud optical depth, and liquid cloud fraction from the MODIS (Moderate Resolution Imaging Spectroradiometer) instruments on board the Aqua and Terra satellites. We then compare the derived susceptibility function to a corresponding estimate from the Norwegian Earth System Model (NorESM). Results compare well between simulations and observations, showing that stratocumulus regions off the west coast of the major continents along with large regions over the Pacific and the Indian Oceans are susceptible. At low and mid latitudes the signal is dominated by the cloud fraction.

We then carry out geo-engineering experiments with a uniform increase over ocean of $10^{-9} \mathrm{~kg} \mathrm{~m}^{-2} \mathrm{~s}^{-1}$ in emissions of sea salt particles with a dry modal radius of $0.13 \mu \mathrm{m}$, an emission strength and areal coverage much greater than proposed in earlier studies. The increased sea salt concentrations and the resulting change in marine cloud properties lead to a globally averaged forcing of $-4.8 \mathrm{~W} \mathrm{~m}^{-2}$ at the top of the atmosphere, more than cancelling the forcing associated with a doubling of $\mathrm{CO}_{2}$ concentrations. The forcing is large in areas found to be sensitive by using the susceptibility function, confirming its usefulness as an indicator of where to inject sea salt for maximum effect.
\end{abstract}

Results also show that the effectiveness of sea salt seeding is reduced because the injected sea salt provides a large surface area for water vapor and gaseous sulphuric acid to condense on, thereby lowering the maximum supersaturation and suppressing the formation and lifetime of sulphate particles. In some areas, our simulations show an overall reduc- tion in the $\mathrm{CCN}$ concentration and the number of activated cloud droplets decreases, resulting in a positive forcing.

\section{Introduction}

There is broad agreement in the scientific community that we now experience a global warming. Due to political inertia and the lack of commitment to mitigation strategies, engineering of the earth's climate has been suggested as an approach to counteract the global warming (Crutzen, 2006; Wigley, 2006). One suggested technique involves increasing the overall negative effect that clouds have on the radiative balance at the top of the atmosphere (TOA). To achieve this, seawater would be sprayed into the air over ocean to increase the number of sea salt particles that act as cloud condensation nuclei (CCN) (Latham, 1990; Latham et al., 2008; Salter et al., 2008). This will increase the albedo of overlying clouds through the first indirect effect (Twomey, 1974). As the ocean surface has a low reflectivity, increasing the albedo of overlying clouds may greatly affect the amount of solar radiation that is reflected from the Earthatmosphere system. This geo-engineering technique was first proposed by Latham (1990) and is considered to be promising, both in terms of performance and affordability (Lenton and Vaughan, 2009; Korhonen et al., 2010).

Several climate model studies have been performed to investigate the effectiveness of sea salt seeding of marine clouds, as well as locations suited for such manipulation. Latham et al. (2008) used two different models (HadGAM and NCAR CAM) to calculate the radiative forcing of changing the cloud droplet number concentration (CDNC) to $375 \mathrm{~cm}^{-3}$ either in all clouds over ocean or in clouds found in selected regions. Similarly, Jones et al. (2009) conducted 
a study using different versions of the HadGEM2 model in which the CDNC was increased to $375 \mathrm{~cm}^{-3}$ in three regions of persistent marine stratocumulus. These studies found that cloud seeding could counteract or limit the warming of the global climate, but Jones et al. (2009) also showed that large regional effects on e.g. the hydrological cycle can be expected. These studies were crude in that they assumed a fixed value of CDNC in all clouds that were seeded, and they made "no attempt to model the aerosol, dynamical or cloud microphysical processes involved" (Jones et al., 2009). Using the GLOMAP global aerosol model, Korhonen et al. (2010) increased emissions of sea salt in certain regions and studied the effect this had on the natural aerosol processes and particle size distributions in the atmosphere. They further parametrised the effect that increased emissions had on the CDNC, but did not include calculations of radiative forcing in the study.

The radiative response of cloud seeding exhibits large spatial variations. Defining the regions that are most susceptible is therefore important, both to achieve the maximum cooling effect possible and to minimize the costs of this climate manipulation strategy (Latham et al., 2008). The objective of this study is to investigate the regional susceptibility of marine clouds to sea salt injections. We have made use of satellite observations to map the regions where an increase in CDNC will affect the reflected solar radiation the most. These susceptible areas are based on a derived cloud-weighted susceptibility function which depends on both cloud albedo, CDNC, solar zenith angle and the observed cloud fraction. We further investigated whether these areas are reproduced by a state-of-the-art climate model, the NorESM (Norwegian Earth System Model). We also conducted simulations in which the emissions of sea salt over ocean were increased. Results from these simulations were used to validate the cloud-weighted susceptibility function and therefore to investigate whether it can be used as an indicator of suited areas for further research on cloud seeding.

In our simulations, the added sea salt changes the overlying clouds through physical processes and we compute the radiative effect of cloud seeding based on these altered cloud properties. In earlier studies, the radiative forcing was found through imposing an assumption of how the CDNC is likely to change in seeded coulds (Latham et al., 2008; Jones et al., 2009). Our results show in what regions the injections of sea salt have the largest impact on the radiative balance at the top of the atmosphere and what magnitude this forcing may reach, in addition to highlighting factors that reduce the effectiveness of cloud seeding.

This study does not include research on the side effects that can result from cloud seeding, nor does it include any treatment of the ethical or political aspects of geoengineering. Here we focus only on mapping susceptible regions and investigating the radiative forcing that can result from using this technique.
In the following section we describe the data and methods used, in addition to defining the susceptibility function. In Sect. 3 we present areas sensitive to CDNC increase based on both satellite data and simulated results. We proceed to investigate results from the geo-engineering experiments in Sect. 4, and then summarize and conclude our findings in Sect. 5.

\section{Data and methods}

\subsection{Satellite data}

The observational data used are from the MODIS (Moderate Resolution Imaging Spectroradiometer) instruments on board the AQUA and TERRA satellites (Platnick et al., 2003), along with parameters retrieved from these data. The satellite products include daily observations of the liquid cloud fraction, the cloud optical depth (COD) and the cloud droplet effective radius (CDR), and are from the Collection 5 processing stream. The collection number indicates what algorithms are used to process the satellite observations (http://modis-atmos.gsfc.nasa.gov/). The COD and CDR are retrieved using the absorption channel at $2.1 \mu \mathrm{m}$ in combination with non-absorbing channels at $0.65,0.86$ and $1.2 \mu \mathrm{m}$ over land, ocean and snow surfaces respectively. The retrievals assume plane-parallel clouds and an overcast scene with cloud homogeneity within the $1-\mathrm{km}$ observation pixel (Platnick et al., 2003; Bréon and Doutriaux-Boucher, 2005). Data on CDNC are taken from the Quaas et al. (2006) data set and are retrieved from the joint histogram of MODIS COD and MODIS CDR for liquid water clouds, and diagnosed assuming adiabatic clouds. The uncertainty in CDNC is largely tied to the uncertainty in retrievals of CDR (Quaas et al., 2006) and to the correctness of the assumption on adiabaticity. The product is more reliable for homogeneous, single-layer clouds than for more complex clouds, and the uncertainty is expected to be lower over ocean than over land surfaces.

\subsection{Model}

The study makes use of the Norwegian Earth System Model (NorESM), which is based on the NCAR (National Center for Atmospheric Research) Community Climate System Model version 4 (CCSM4). The NorESM includes several modifications to the treatment of atmospheric chemistry, aerosols, and clouds, along with replacement of the model ocean component. The aerosol microphysics is described in detail by Seland et al. (2008) and includes five prognostic aerosol species (sea salt, sulphate $\left(\mathrm{SO}_{4}\right)$, particulate organic matter, black carbon and mineral dust) as well as two gaseous aerosol precursors producing sulfate (DMS and $\mathrm{SO}_{2}$ ). The model uses the Mårtensson et al. (2003) scheme for wind speed dependent sea salt emissions, which were fitted to the NorESM sea salt size distribution by Struthers et al. (2011) 
and have dry modal radii of $0.022 \mu \mathrm{m}, 0.13 \mu \mathrm{m}$ and $0.74 \mu \mathrm{m}$ and geometric standard deviations of $1.59,1.59$ and 2.0, respectively.

The aerosol indirect effect is included in the model, as described by Hoose et al. (2009). It is evaluated through the AeroCom (Aerosol Comparisons between Observations and Models) project along with the direct aerosol radiative effect and the simulated aerosol fields (e.g. Penner et al., 2006; Koch et al., 2009; Quaas et al., 2009). In the latest published quantification, the atmospheric component of NorESM (CAM-Oslo) had an indirect effect of $-1.9 \mathrm{Wm}^{-2}$ compared to an AeroCom mean of $-1.6 \mathrm{Wm}^{-2}$ (Quaas et al., 2009). Since then the model has been modified and the value is now around $-1 \mathrm{Wm}^{-2}$ (A. Kirkevåg, personal communication, 2012), as discussed in an upcoming paper. The model uses a two moment warm cloud microphysical scheme described by Storelvmo et al. (2006) and Hoose et al. (2009), the Abdul-Razzak and Ghan (2000) cloud droplet nucleation scheme with parametrized updraft velocities following Morrison and Gettelman (2008), and an auto-conversion parametrisation following Rasch and Kristjánsson (1998). The in-cloud updraft velocity averaged up to $2 \mathrm{~km}$ height has been shown to be between $10 \mathrm{~cm} \mathrm{~s}^{-1}$ and $40 \mathrm{~cm} \mathrm{~s}^{-1}$ over ocean (Hoose et al., 2010, Fig. 6).

The atmospheric component of the model runs with a horizontal resolution of $1.9^{\circ} \times 2.5^{\circ}$ and 26 levels in the vertical. The model was run offline, meaning that the meteorological evolution is the same in all simulations. We can therefore study the effect of sea salt on clouds and the radiative balance without noise due to feedbacks from the aerosol forcing. This also implies that aerosol effects on cloud cover and lifetime are not fully simulated in this study. The contribution to the second indirect effect associated with changes in cloud liquid water due to suppression of precipitation release is accounted for following Kristjánsson (2002). The control run uses year 2000 greenhouse gas concentrations and year 2000 CMIP 5 aerosol emissions, while geo-engineering simulations run with additional sea salt particles. All results presented are five year averages of daily model output. The two-dimensional fields of cloud droplet effective radius and CDNC are vertical averages weighted by the cloud fraction.

The ocean component of the model is based on the Miami Isopycnal Coordinate Ocean Model (MICOM) (Bleck and Smith, 1990; Bleck et al., 1992) with several modifications, many of them described in Assmann et al. (2010).

\subsection{Susceptibility function}

The goal of this study is to define areas that experience large changes in reflected solar radiation with CDNC increase. To do this, we introduced a simple function for the normalised sensitivity of cloud albedo to changes in CDNC: $f=\frac{\frac{\mathrm{d} A}{\mathrm{~d} N}}{\max \left(\frac{\mathrm{d} A}{\mathrm{~d} N}\right)}$

where $A$ is the cloud albedo and $N$ is used as an abbreviation of CDNC. The change in albedo with CDNC, defined as cloud susceptibility, is given by (Twomey, 1991):

$\frac{\mathrm{d} A}{\mathrm{~d} N} \approx \frac{A(1-A)}{3 N}$

and it is clear that this quantity is largest for intermediate $A$ $(0.5)$ and small $N\left(N_{\min }\right)$ :

$\max \left(\frac{\mathrm{d} A}{\mathrm{~d} N}\right)=\frac{0.5(1-0.5)}{3 N_{\min }}=\frac{1}{12 N_{\min }}$

By inserting into Eq. (1) we get:

$f=4 A(1-A) \cdot \frac{N_{\min }}{N}$

The effect of the cloud albedo change on the global radiative budget depends on the amount of shortwave (SW) radiation available. Therefore, Eq. (4) was multiplied by a weighting function, $f_{\mathrm{za}}(\epsilon[0,1])$, to account for the solar zenith angle, with 1 representing an overhead sun and 0 representing a sun below the horizon. The resulting function is referred to as the susceptibility function:

$f_{\text {susc }}=4 f_{\text {za }} \cdot A(1-A) \cdot \frac{N_{\text {min }}}{N}$

The overall radiative effect of changes in CDNC is determined by both this in-cloud susceptibility and the frequency of occurrence of the susceptible clouds. Therefore, the susceptibility function was multiplied by the cloud fraction, $f_{\text {cf }}$, to find areas that would experience the largest change in the $\mathrm{SW}$ reflection per unit change in CDNC. The cloud-weighted susceptibility function is given by:

$f_{\mathrm{c}-\text { w_susc }}=4 f_{\mathrm{za}} \cdot A(1-A) \cdot \frac{N_{\text {min }}}{N} \cdot f_{\text {cf }}$

The $N_{\min }$ chosen in Eqs. (5) and (6) is of crucial importance for the absolute magnitude of the cloud-weighted susceptibility. However, in this study the purpose is to find what areas over ocean are more sensitive than others, and then the value of $N_{\min }$ is not important. The minimum value of CDNC is approximately $20 \mathrm{~cm}^{-3}$ in the Quaas et al. (2006) data set and, for consistency, we chose to use this value both when computing the simulated and the observed susceptibility. This value is only used in post-processing and does not affect the simulations themselves.

In order to calculate cloud albedo, we used a simple relation between optical thickness, $\tau$, and albedo from Hobbs (1993), assuming an asymmetry factor of 0.85 :

$A \approx \frac{\tau}{(\tau+6.7)}$ 
and for model results the optical thickness was calculated based on cloud droplet effective radius $\left(r_{\mathrm{e}}\right)$, cloud liquid water path (LWP) and the density of liquid water $\left(\rho_{\mathrm{L}}\right)$ following e.g. Liou (2002):

$\tau=\frac{3}{2} \frac{\mathrm{LWP}}{\rho_{\mathrm{L}} r_{\mathrm{e}}}$

The cloud-weighted susceptibility function can be compared to a data resource created by Sortino (2006). Sortino found areas suited for cloud seeding by weighting different selection criteria, with data from ISCCP (International Satellite Cloud Climatology Project) and ECMWF (European Centre for Medium-Range Weather Forecasts). These criteria were based on both cloud susceptibility and on technical aspects of the seeding process from Salter et al. (2008). To date, the only scientific study published on spray design is that of Salter et al. (2008). Here we chose not to limit our research based on the findings of that study, as a potential implementation of geo-engineering is well into the future. Instead, we use a more general approach that has the advantage of being easier to use on any data set, in addition to ensuring that we do not exclude regions that are highly susceptible if the emission strategy is changed. Also, the cloud-weighted susceptibility can easily be calculated from both satellite observations and simulated data, which makes this approach well suited for model validation.

\section{Cloud susceptibility}

\subsection{Sensitive areas: MODIS}

The annually averaged susceptibility function (Eq. 5) applied to MODIS retrievals (Fig. 1a) indicates where a given change in CDNC would have the largest in-cloud effect on the SW flux reflected from the earth-atmosphere system. Figure 1a shows that large regions between $30^{\circ} \mathrm{S}$ and $30^{\circ} \mathrm{N}$ are susceptible, especially clean regions with low aerosol concentrations (not shown) in the Pacific and Indian oceans, along with regions in the western Atlantic. The geographical pattern of susceptibility is very similar to the inverse of the CDNC field (not shown), that is, the susceptibility is in general large where the CDNC is low (Eq. 5). Similarly, the susceptible areas are closely co-located with regions of large cloud droplet effective radii. Using MODIS data Oreopoulos and Platnick (2008) mapped what they called absolute susceptibility, that is the radiative response of an absolute increase in CDNC, and their regions of high susceptibility compare very well with our findings.

Figure 2a shows the annually averaged liquid mean cloud cover from MODIS retrievals, while Fig. $2 b$ shows the annually averaged cloud-weighted susceptibility (Eq. 6) from MODIS. The fraction of liquid clouds is used in the calculation of cloud-weighted susceptibility for consistency as the CDNC data set is based on observations of liquid clouds (Quaas et al., 2006). Also, the sea salt is to be emitted close a.

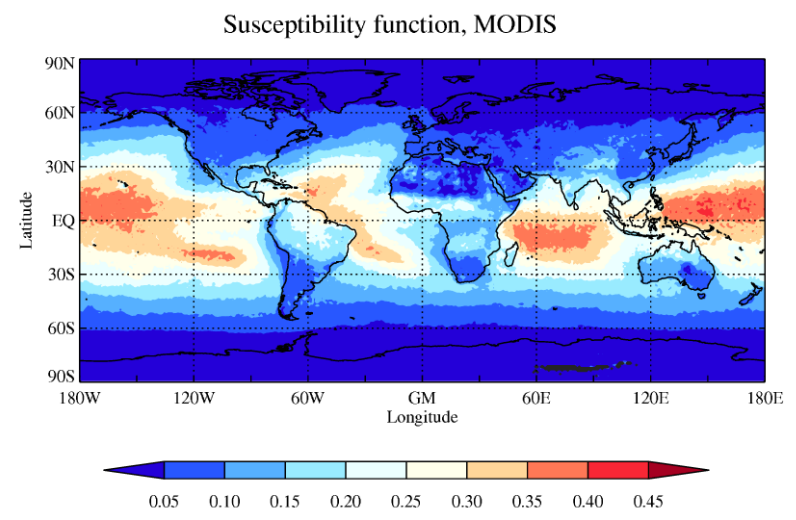

b.

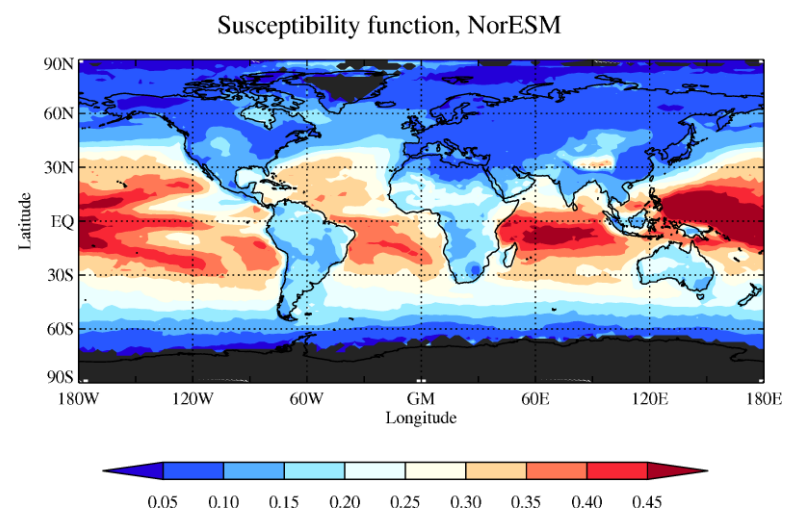

Fig. 1. Annually averaged susceptibility (Eq. 5) from (a) MODIS data and (b) NorESM simulations.

to the ocean surface and is expected to influence liquid clouds at low altitudes the most (Salter et al., 2008). Comparing the cloud-weighted susceptibility (Fig. 2b) to Figs. 1a and 2a indicates that at low and mid latitudes the function (Eq. 6) is dominated by the cloud fraction rather than by the susceptibility. One exception is the area of high cloud-weighted susceptibility over the Indian Ocean, which is influenced by a high susceptibility (Fig. 1a). Overall, the most susceptible areas (Fig. 1a), corresponding to regions of low CDNC, have small cloud fractions (Fig. 2a). Regions of high cloudweighted susceptibility include ocean regions off the west coasts of the major continents, including the stratocumulus regions off the coasts of Namibia, Peru, North America and Australia, along with clean regions over the Indian and the Pacific oceans.

Figure 3 shows the seasonal shift in the cloud-weighted susceptibility, with regions of high signals over the summer hemisphere. This is caused by both the seasonal change in cloud regimes and shifts in the solar zenith angle weighting function, $f_{\text {za }}$ (Eq. 6).

\subsection{Earlier findings}

Earlier studies on marine cloud seeding (Salter et al., 2008; Jones et al., 2009; Korhonen et al., 2010) have focused on 
a.

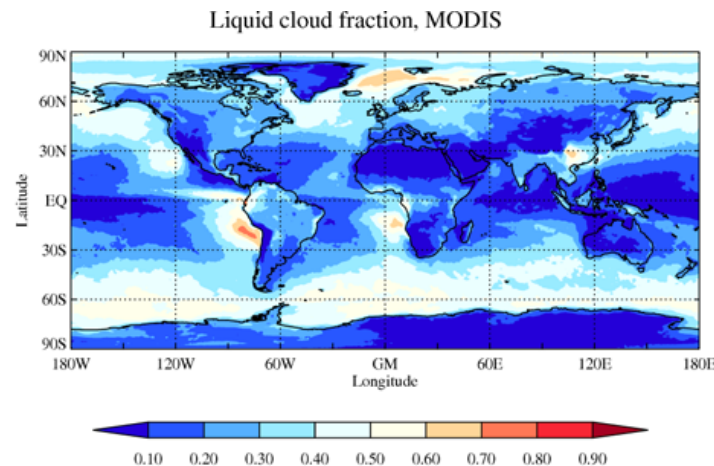

c.

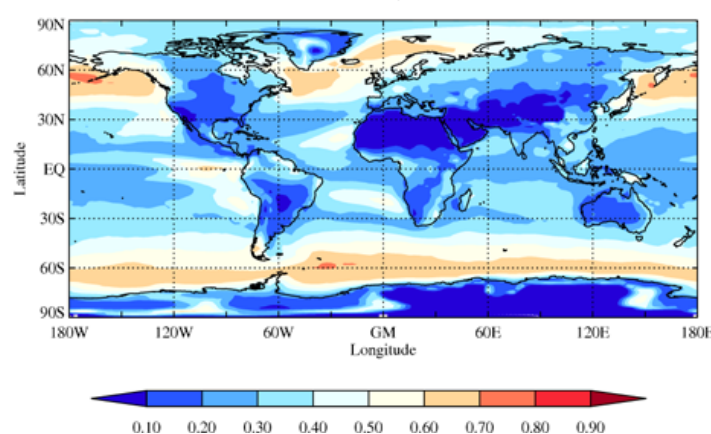

b.

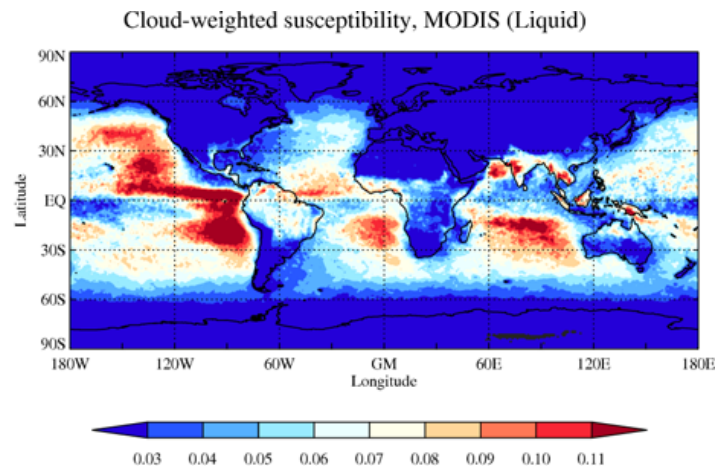

d.

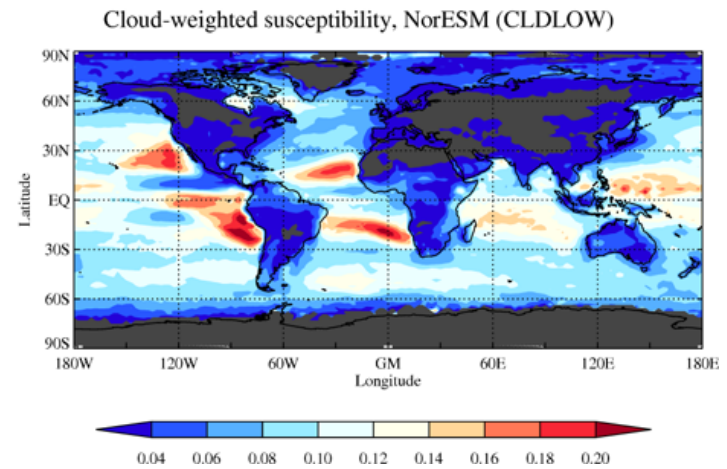

Fig. 2. (a) Liquid mean cloud fraction from MODIS data, (b) cloud-weighted susceptibility from MODIS data, (c) low cloud fraction from NorESM, (d) cloud-weighted susceptibility from NorESM simulations. All annual means. Please note that color bars differ.

a.

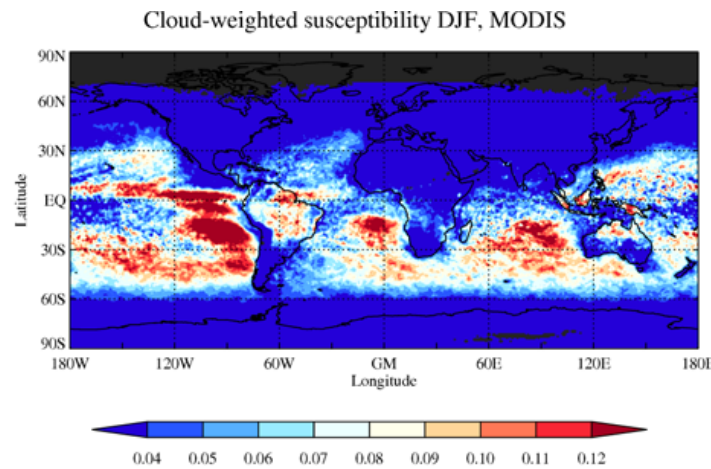

c.

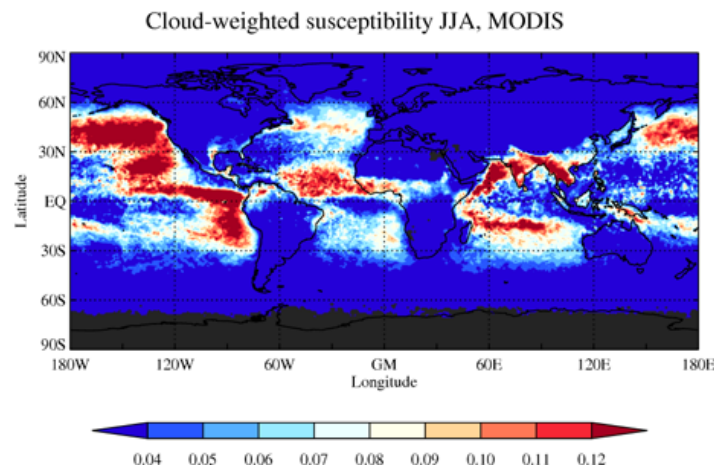

b.

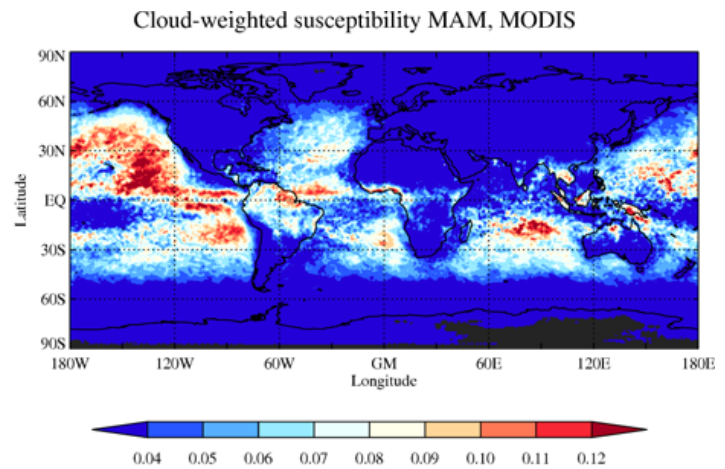

d.

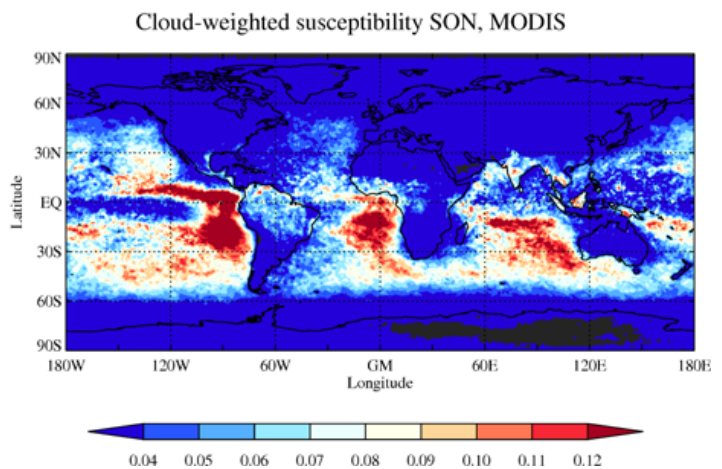

Fig. 3. Cloud-weighted susceptibility from MODIS retrievals: (a) December, January, February mean, (b) March, April, May mean, (c) June, July, August mean, (d) September, October, November mean. 
the stratocumulus regions off the west coasts of the continents. Salter et al. (2008) used the data resource and algorithm of Sortino (2006) to find these sites based on cloud susceptibility and technical aspects of the seeding process. These sensitive regions are reproduced in our study (Fig. 2b), while we also find a high cloud-weighted susceptibility just north of the equator over the Pacific Ocean not found in Salter et al. (2008). Differences between the studies include both what parameters are included in the selection process and the observational data used. The Sortino satellite data set is comprised of ISCCP data, while this study is based on satellite observations made by the MODIS instruments. These data sets differ both in spatial and temporal resolution, and the global difference in cloud fraction between the two sets is especially large over ocean (Pincus et al., 2011). The high spectral resolution of the MODIS data leads to high quality retrievals of cloud properties such as cloud optical depth and size of both droplets and ice particles (Pincus et al., 2011).

We note that the cloud-weighted susceptibility also has similarities with the relative susceptibility defined by Platnick and Oreopoulos (2008); the radiative response of a relative increase in the CDNC. This relative susceptibility is given as the absolute susceptibility (see Sect. 3.1) multiplied by the CDNC. We found in Sect. 3.1 that the absolute susceptibility compared well to our susceptibility function (Eq. 5). The similarities between relative susceptibility from Platnick and Oreopoulos (2008) and the cloud-weighted susceptibility found here therefore indicate that the CDNC in general is high where the cloud fraction is high. This relation could conceivably result from satellite retrievals of broken clouds with weak updrafts, low CDNC and small cloud fractions contrasting vigorous clouds with strong updrafts, high CDNC and large cloud fractions. Similarly, areas of low cloud fractions at the fringes of frontal systems may have small updraft velocities and therefore low CDNC. The relation could also be spurious and based on a bias in satellite retrievals of low cloud fractions. If the cloud optical depth is underestimated, this will lead to an underestimation of the CDNC. An in depth discussion of this relation is beyond the scope of this paper.

\subsection{Sensitive areas: NorESM}

The in-cloud susceptibility (Eq. 5) simulated by the NorESM is large in vast regions over the Pacific and Indian Oceans (Fig. 1b), largely corresponding to the regions found to be sensitive by use of observational data (Fig. 1a). The region between $30^{\circ} \mathrm{S}$ and $30^{\circ} \mathrm{N}$ is especially susceptible in both cases, but the simulated results show a region of high susceptibility off the coast of Peru which is not found using the MODIS data.

The magnitude of the susceptibility is systematically larger in the simulated case than in the observations. This is caused by differences in the cloud optical depth and in the
CDNC between observations and simulations. In the current set up, the NorESM susceptibility is based on the optical depth of all clouds that contain liquid, while the optical depth used for the MODIS susceptibility calculations included the all-liquid clouds only. The cloud optical depth, which determines the cloud albedo via Eq. (7), is generally higher in the simulations than in the observations, except in the stratocumulus regions. The opposite is true for the CDNC, that is, the magnitude of CDNC in the simulations is lower than in the Quaas et al. (2006) data set. Combined, these discrepancies make the magnitude of the susceptibility function larger in the simulated than in the observed case. The purpose of the maps of sensitive areas is to find out where increased emissions of sea salt are most likely to have a large effect on the amount of SW radiation reflected by the earthatmosphere system. The magnitude of the susceptibility is therefore of little importance. A large susceptibility will, however, lead to it having a large weight when calculating the cloud-weighted susceptibility and the difference in relative importance of the susceptibility function and the cloud fraction will therefore influence the results.

The cloud-weighted susceptibility (Eq. 6) calculated from NorESM data is shown in Fig. $2 \mathrm{~d}$ and a plot of low level (pressure $>700 \mathrm{hPa}$ ) cloud cover in Fig. 2c. Note that the simulated cloud-weighted susceptibility is based on the low level, rather than the liquid, cloud fraction. As in the case when observations were used, the simulated cloud-weighted susceptibility (Fig. 2d) is largely influenced by the persistent cloud decks in the stratocumulus regions (Fig. 2c). Here, however, the susceptible areas over the Pacific Ocean, especially to the north east of Indonesia, are more important than what was found from observations. From Fig. $2 \mathrm{c}$ it is clear that the fraction of low clouds in these regions is larger than the fraction of liquid clouds observed from MODIS (Fig. 2a). This discrepancy may be due to model uncertainties or due to a fraction of the clouds included in the low cloud fraction containing ice. It may also be caused by overlying mixed phase or ice clouds blocking the satellite instruments from observing low level liquid clouds as often as they occur. A high cloud fraction in remote areas where the susceptibility is large (Figs. 2c and 1b), leads to both stratocumulus regions and the cleaner regions over the Pacific Ocean having high cloud-weighted susceptibilities (Eq. 6). The model does not reproduce the relative strength of the signals found off the west coasts of Canada and India from MODIS retrievals.

We note that the temporal resolution of the data influences the susceptibility calculations. We use daily data from both MODIS and NorESM for consistency. Repeating the calculations using monthly averaged model results gave a higher magnitude susceptibility, and therefore a larger cloudweighted susceptibility (not shown).

The regions found to have high cloud-weighted susceptibility by using simulated results in general agree well with the regions found from observational data, but region by region the model has a higher susceptibility to cloud seeding 
than what is found from observations. This is because both the susceptibility and the cloud fraction are larger in the simulated than in the observed case.

\section{Geo-engineering simulations using NorESM}

Comparing the simulated cloud-weighted susceptibility to the simulated radiative forcing resulting from increased sea salt emissions opens for validation of the cloud-weighted susceptibility function. Additionally, through such experiments we can take a first step in investigating the effectiveness of this geo-engineering technique; how large is the radiative forcing resulting from sea salt injections and what limits its effectiveness?

The experiments consisted of simulations in which the emissions of sea salt were increased uniformly over open ocean by $10^{-9} \mathrm{~kg} \mathrm{~m}^{-2} \mathrm{~s}^{-1}$. These sea salt emissions had a number mean dry modal radius of $0.13 \mu \mathrm{m}$ and a geometric standard deviation of 1.59 , which corresponds to an effective radius of $0.18 \mu \mathrm{m}$. For comparison, Latham (2002) suggested using monodisperse emissions of sea salt particles with a radius of $0.13 \mu \mathrm{m}$. The total emission flux is equivalent to a global emission rate of about 350 tonnes of sea salt per second.

This study simulates the effect of increasing emissions of sea salt rather than increasing the CDNC of the clouds directly (Latham et al., 2008; Jones et al., 2009). We ignore technological concerns such as wind speed dependent spray rate, homogeneous versus inhomogeneous spraying and the remoteness of the regions for technical support (Latham et al., 2008; Salter et al., 2008). Instead a more general approach was used and we recognize that as of today the emissions modeled here are not technically feasible. Uniformly increasing emissions includes emissions in regions where the surface wind speed and therefore the natural emissions of sea salt are low. The effects of such an increase may therefore be larger than the effects of emissions that are wind speed dependent. However, uniform injections also include emissions in regions that experience negative vertical velocities, which will decrease the lifetime of the emitted particles. The great advantage of using a uniform injection rate is that this points to the geographical regions that are most sensitive to the added sea salt particles and where a given increase in emissions will have the largest effect on the radiative balance at the TOA.

\subsection{Validation of the cloud-weighted susceptibility function}

To investigate whether the cloud-weighted susceptibility function is a good indicator of the impact of sea salt seeding, we compared the change in radiative balance at the TOA due to aerosol-cloud interactions (Fig. 4a) to the map of cloud-weighted susceptibility (Fig. 2d). The comparison a.

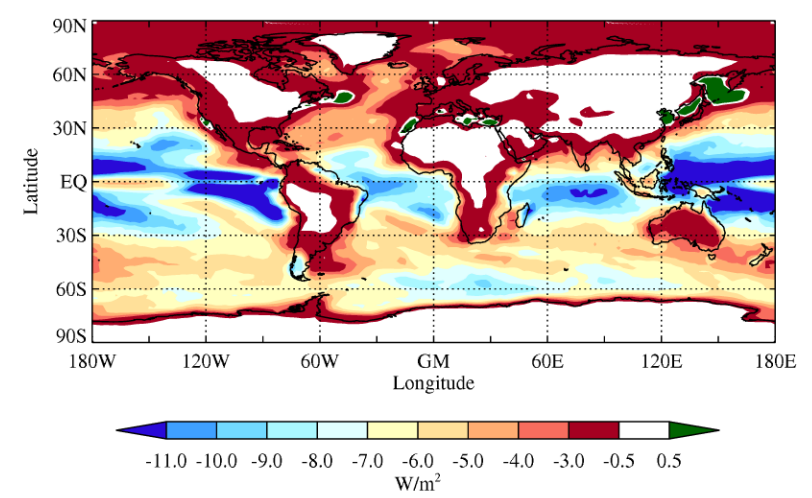

b.

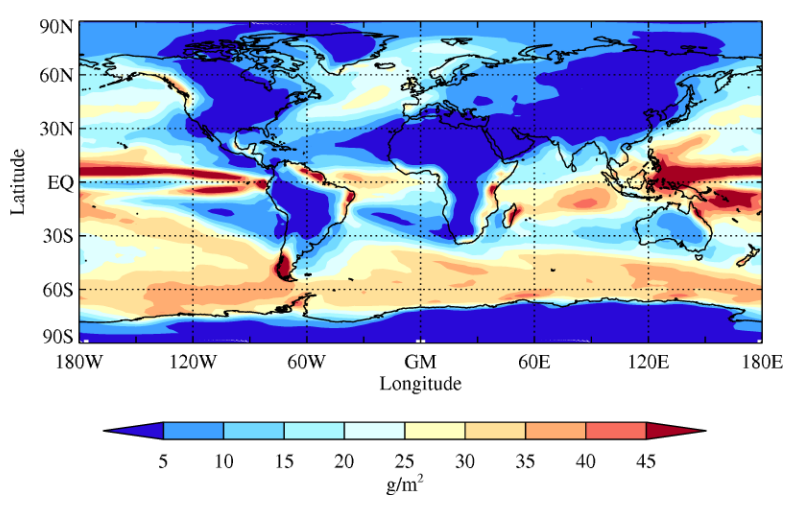

Fig. 4. NorESM: (a) change in TOA radiative flux $\left(\mathrm{W} \mathrm{m}^{-2}\right)$ due to aerosol-cloud interactions, (b) change in cloud liquid water path $\left(\mathrm{g} \mathrm{m}^{-2}\right)$. Both annual means.

reveals that the regions found to have high cloud-weighted susceptibilities correlate well with regions of high impact from sea salt emission increase. Inconsistencies include areas along the equator over the Atlantic Ocean and the relative strength of the signals over the Indian and over the western and mid Pacific Ocean. Figure 4b shows the annually averaged change in cloud liquid water path, which is a result of the change in precipitation release following autoconversion dependence on cloud droplet size (Kristjánsson, 2002). This second aerosol indirect effect is not included in the cloudweighted susceptibility function and leads to discrepancies between results of this function (Fig. 2d) and the change in radiative balance at the TOA (Fig. 4a).

In general, however, sensitive regions between $30^{\circ} \mathrm{S}$ and $30^{\circ} \mathrm{N}$ found by combining the susceptibility function (Eq. 5) with low level cloud cover $(>700 \mathrm{hPa})$ are good indicators of where the seeding of marine clouds strongly impacts the Earth's radiative budget. The cloud-weighted susceptibility thus contains information about what regions should be suited for further research on geo-engineering. 


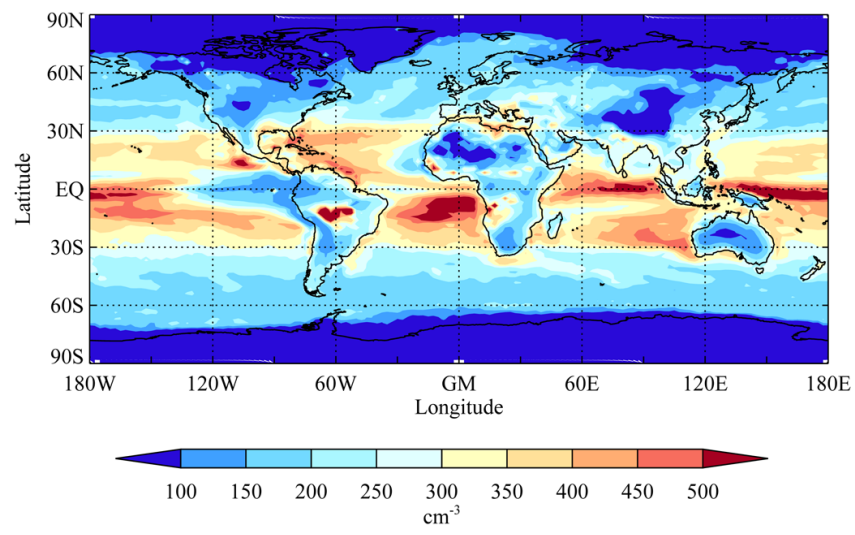

Fig. 5. NorESM: cloud droplet number concentration $\left(\mathrm{cm}^{-3}\right)$ after adding sea salt of a dry modal radius of $0.13 \mu \mathrm{m}$. Annual mean at $\sim 930 \mathrm{hPa}$.

\subsection{Effects of increasing sea salt emissions}

The radiative forcing at TOA resulting from aerosol-cloud interactions following increased emissions of $0.13 \mu \mathrm{m}$ sea salt is shown in Fig. 4a. The negative values indicate that more solar radiation was reflected from the earth-atmosphere system in the case of added sea salt than in the control run, with a globally averaged radiative forcing of $-4.8 \mathrm{~W} \mathrm{~m}^{-2}$. By comparison, a doubling of $\mathrm{CO}_{2}$ concentrations in the atmosphere has a positive forcing of approximately $3.7 \mathrm{~W} \mathrm{~m}^{-2}$, and the magnitude of the forcing from increased cloud reflectivity may therefore be sufficient to counteract global warming, depending on future greenhouse gas concentrations.

In earlier studies Latham et al. (2008) and Jones et al. (2009) estimated the radiative forcing resulting from seeding of marine clouds by assuming a homogeneous and fixed CDNC value of $375 \mathrm{~cm}^{-3}$ or $1000 \mathrm{~cm}^{-3}$ in seeded clouds. Figure 5 shows the annually averaged CDNC around $930 \mathrm{hPa}$ after cloud seeding and clearly indicates that assuming a fixed value is inappropriate. The resulting CDNC field is highly non-uniform, which was also found by Korhonen et al. (2010). This explains why the resulting radiative forcing (Fig. 4a) does not have the same geographical pattern as that of Latham et al. (2008), discrepancies being especially large in the Mid- and the West-Pacific.

The radiative forcing shown in Fig. $4 \mathrm{a}$ also include areas that experience a positive forcing and Fig. 5 shows that even though we emit a sea salt mass about 70 times larger than what was suggested by Latham et al. (2008), the average CDNC over ocean is below their assumed value of $375 \mathrm{~cm}^{-3}$ in seeded conditions. There may be several reasons for this. The NorESM model computes droplet nucleation based on aerosol number concentration, size distribution and cloud supersaturation. Our results show that increasing the number of sea salt particles in the atmosphere affects both the cloud supersaturation (Fig. 6a) and the background aerosols (Fig. 6b and c), in addition to affecting the concentration of CCN di- rectly. The maximum supersaturation reached is reduced because of an increased competition effect following sea salt injections (e.g. Bower et al., 2006; Korhonen et al., 2010). Independent of whether the added sea salt particles are large enough to become activated to cloud droplets, they will swell and create a moisture sink in an updraft. The reduced maximum supersaturation leads to an increase in the critical minimum size of particles that can activate to become cloud droplets. This may inhibit activation of both the added sea salt and the pre-existing aerosols that would activate without sea salt injections (Ghan et al., 1998).

The sea salt injections will also influence the concentration of particulate sulfate $\left(\mathrm{SO}_{4}\right)$ in the atmosphere. When gaseous sulphuric acid reaches saturation two things can happen; it can either condense on pre-existing particles or it can nucleate to form new particles. The added sea salt particles greatly increase the total surface area of atmospheric aerosols, allowing more condensation to occur, reducing the both the nucleation of new $\mathrm{SO}_{4}$ particles (Fig. 6b) and the lifetime of $\mathrm{SO}_{4}$ (Fig. 6c) as more is washed out with the sea salt. The respective effects on background aerosols have yet to be quantified, but Fig. $6 \mathrm{~b}$ shows that sea salt injections of this magnitude lead to an almost complete shutoff of $\mathrm{SO}_{4}$ nucleation in our simulations. Both the effect on supersaturation and the effect on the $\mathrm{SO}_{4}$ concentration lead to a reduced effectiveness of sea salt injections.

Figure $6 \mathrm{~d}$ shows the percent time with a decrease in column integrated CDNC. Ocean regions where this number is high are co-located with regions of small negative or positive forcing estimates in Fig. 4a, indicating that the positive forcing occurs when the added sea salt leads to the opposite effect of that desired. The decrease in column CDNC over land surfaces has little influence on the radiative budget both because of the large surface albedo and because these clouds generally have high CDNC and their albedo is less sensitive to changes in this quantity (Eq. 2).

Figure 6 and the associated discussion show that adding particles that are too small to become activated may lead to a decrease in the reflection of solar radiation through their effect on the supersaturation and the activation of background aerosols. This is a reminder that there are many non-linear effects which need to be accounted for before one can start planning to perform this type of geo-engineering. The importance of the size of the injected particles will be investigated further in an upcoming paper. The above-mentioned limitations were not accounted for in Latham et al. (2008) and Jones et al. (2009).

To fully investigate the effects of uniform cloud seeding we study changes in both atmospheric and cloud microphysical conditions. The annually averaged change in column burden sea salt resulting from the $0.13 \mu$ m mode sea salt increase is shown in Fig. 7a. This change is influenced by both the emissions and the atmospheric conditions prevailing at any given model point. Convergence, updraft, and dry atmospheric conditions will lead to an increased lifetime of 
a.

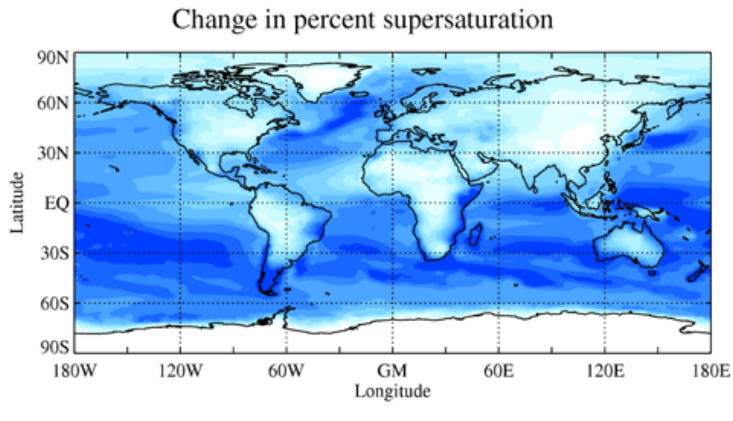

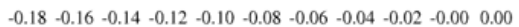

c.

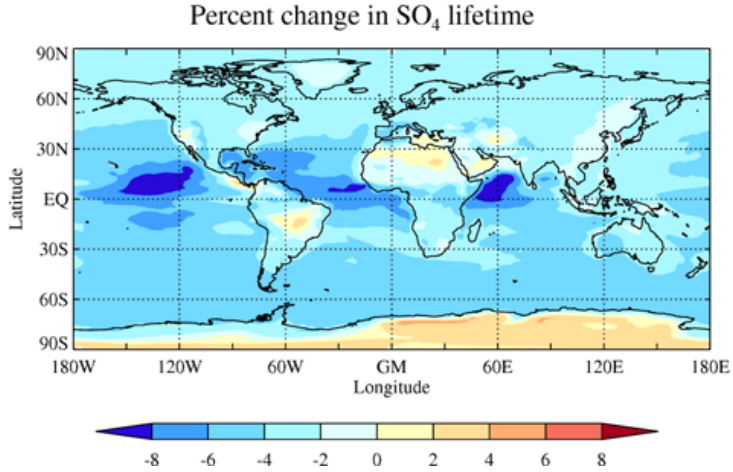

b.

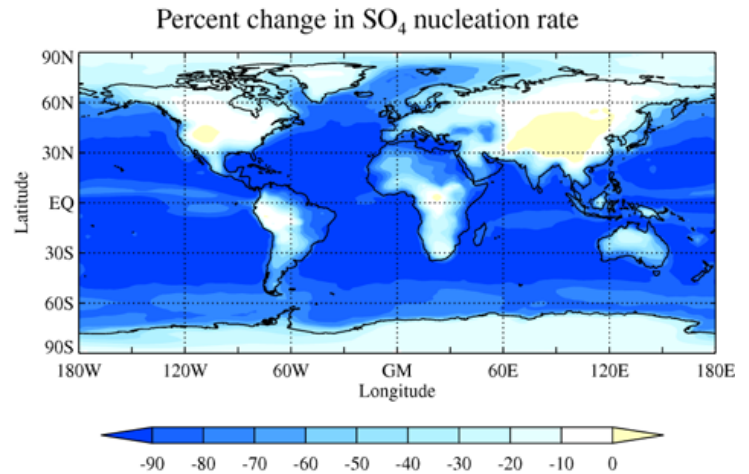

d.

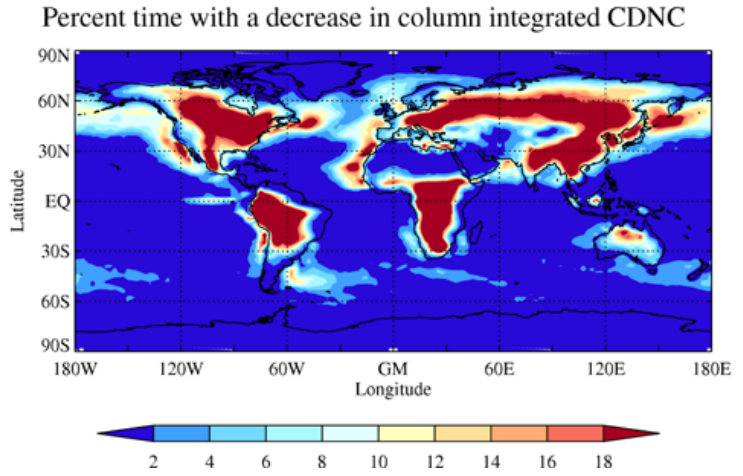

Fig. 6. NorESM: (a) change in percent cloud supersaturation with respect to water at $\sim 930 \mathrm{hPa}$, (b) percent change in $\mathrm{SO}_{4}$ nucleation rate at $\sim 930 \mathrm{hPa}$, (c) percent change in $\mathrm{SO}_{4}$ lifetime, and (d) percent time with a decrease in column integrated CDNC. All annual means.

the added sea salt, while divergence, downdrafts, high relative humidity and precipitation will have the opposite effect. Neither this plot nor the plot of relative change in column burden sea salt (not shown) show similarities with the radiative forcing resulting from added sea salt (Fig. 4a). This indicates that the cloud fraction and the cloud properties dominate the radiative effect of cloud seeding.

Vertically integrated and annually averaged changes in CDNC (Fig. 7b) are generally large in regions where the susceptibility is large (Fig. 1b) because the susceptibility is inversely proportional to CDNC (Eq. 5). The additional sea salt particles lead to a first indirect effect, increasing the CDNC by partitioning the cloud condensate between an increased number of droplets, each having a smaller radius. The changes in cloud droplet effective radius around $930 \mathrm{hPa}$ are shown in Fig. 7c.

We now turn to zonally and annually averaged vertical cross sections of the changes in sea salt concentrations, aerosol concentrations, CDNC and effective radius in Fig. 8. The concentration of sea salt over ocean before seeding is close to bimodal, with the largest vertical extent around 15$20^{\circ} \mathrm{S}$ and $15-20^{\circ} \mathrm{N}$ (not shown) and secondary peaks around $45^{\circ} \mathrm{S}$ and $45^{\circ} \mathrm{N}$. The changes in this concentration with an increased $0.13 \mu \mathrm{m}$ sea salt mode are shown in Fig. 8a, displaying the largest increases between the peaks in concentration, that is around the equator and around $30^{\circ} \mathrm{S}$ and $30^{\circ} \mathrm{N}$.
Large changes occur in regions where convergence and updraft or low relative humidity increase the lifetime of the added sea salt. This pattern of change follows from the uniform increase in emissions. Large changes where sea salt emissions are naturally low due to low surface wind speeds greatly affect cloud properties and it is possible that large benefits would follow from finding an experimental design that allows for emissions that are independent of the surface winds.

Figure $8 \mathrm{~b}$ shows that the largest changes in aerosol number concentration with height occur below $900 \mathrm{hPa}$, with peaks around the equator and around $40^{\circ} \mathrm{S}$ and $50^{\circ} \mathrm{N}$. The corresponding change in CDNC with height (Fig. 8c) is large in a band between $40^{\circ} \mathrm{S}$ and $30^{\circ} \mathrm{N}$, between the surface and about $900 \mathrm{hPa}$. This pattern of change is caused by large changes in the concentrations of sea salt particles, combined with a competition effect that reduces the supersaturation to the north of the equator due to high aerosol concentrations in the control run. The zonally and annually averaged change in cloud droplet effective radius, $r_{\mathrm{e}}$, is shown in Fig. 8d. This change is proportional to the relative change in CDNC and to $r_{\mathrm{e}}$ itself: By assuming that the cloud water content is constant (first indirect effect) and that the cloud droplet mean volume radius is proportional to $r_{\mathrm{e}}$, the change in $r_{\mathrm{e}}$ is given by:

$\Delta r_{\mathrm{e}} \propto-\frac{1}{3} \frac{\Delta N}{N} \cdot r_{\mathrm{e}}$ 
a.

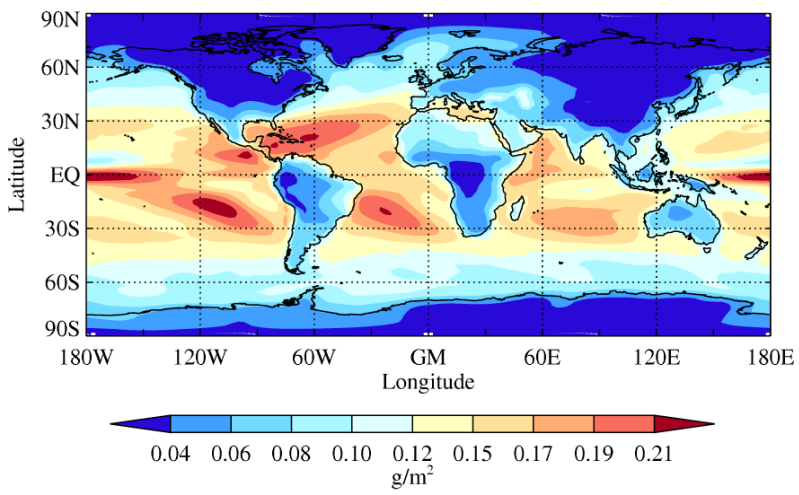

b.

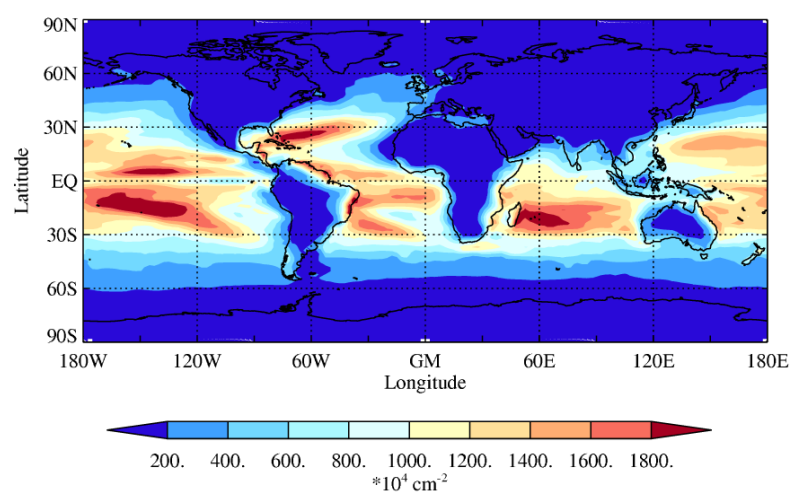

c.

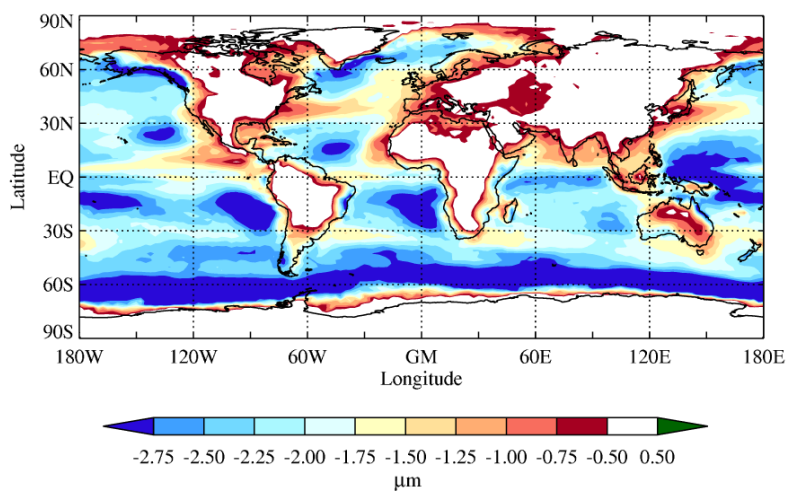

Fig. 7. Changes due to increased sea salt emissions (NorESM): (a) column integrated sea salt $\left(\mathrm{g} \mathrm{m}^{-2}\right)$, (b) column integrated cloud droplet number concentration $\left(\mathrm{cm}^{-2}\right)$, and (c) effective cloud droplet radius $(\mu \mathrm{m})$ at $\sim 930 \mathrm{hPa}$. All annual means.

Figure $8 \mathrm{~d}$ shows that the change in $r_{\mathrm{e}}$ is largest below $800 \mathrm{hPa}$ and has maxima around $20-60^{\circ} \mathrm{S}$ and $60^{\circ} \mathrm{N}$, where $r_{\mathrm{e}}$ is large in the control run (not shown). The relative change in CDNC is much smaller above than below $800 \mathrm{hPa}$.

The simulated radiative forcing resulting from added sea salt is subject to uncertainties and is model dependent. For instance, the total cloud fraction in NorESM is underestimated compared to MODIS (not shown), which may lead to an underestimation of the forcing from the aerosol indirect effect, while the low CDNC in the model makes the clouds very susceptible to added sea salt (Eq. 5) and may lead to an overestimation. Additionally, the albedo of the simulated clouds is closer to 0.5 than the observed albedo, making the reflective properties of the clouds more susceptible to change with respect to CDNC (Eq. 3). Wang et al. (2011) studied the cloud albedo response to injections of $\mathrm{CCN}$ using a cloud resolving model. Their results show that the effectiveness of cloud seeding depends strongly on the spatial distribution of the $\mathrm{CCN}$ injections, the meteorological conditions and on the background aerosol conditions. These parameters are generally not well resolved in global models. As of today, however, using earth system models such as the NorESM is the only possible way to estimate the climatic effect of sea salt injections.

\section{Summary and conclusions}

In this study we have used observations from MODIS retrievals and the Norwegian Earth System Model to investigate what regions over the ocean are most sensitive to deliberate increases in the cloud droplet number concentration. The sensitive regions were located by deriving a cloudweighted susceptibility function that indicates where an increase in CDNC will have the largest effect on the reflected solar radiation, based on cloud albedo, CDNC, solar zenith angle and cloud fraction. Furthermore, we have conducted geo-engineering simulations: (i) to test whether the areas found to be sensitive are co-located with regions where sea salt injections have a large impact on the reflected solar radiation, (ii) to investigate what magnitude the change in reflected radiation may reach, and (iii) to study factors that may reduce the effectiveness of cloud seeding.

Our main findings are:

- The cloud-weighted susceptibility function is a good indicator of where sea salt injections are most effective.

- The areas where sea salt seeding has the largest radiative effect include: large regions mainly between $30^{\circ} \mathrm{S}$ and $30^{\circ} \mathrm{N}$, especially clean regions over the Indian Ocean and the stratocumulus regions off the west coasts of South America, North America, southern Africa and Australia. These areas correspond well with the findings of Salter et al. (2008), except for areas just north of the equator in the Pacific Ocean where our results show a large cloud-weighted susceptibility.

- The regions found to have high cloud-weighted susceptibility agree fairly well between observational data from MODIS and NorESM simulations, but region by region the model shows a higher cloud-weighted susceptibility than what is found from observations.

- Averaged annually and globally, the radiative forcing resulting from a uniform $10^{-9} \mathrm{~kg} \mathrm{~m}^{-2} \mathrm{~s}^{-1}$ increase in 

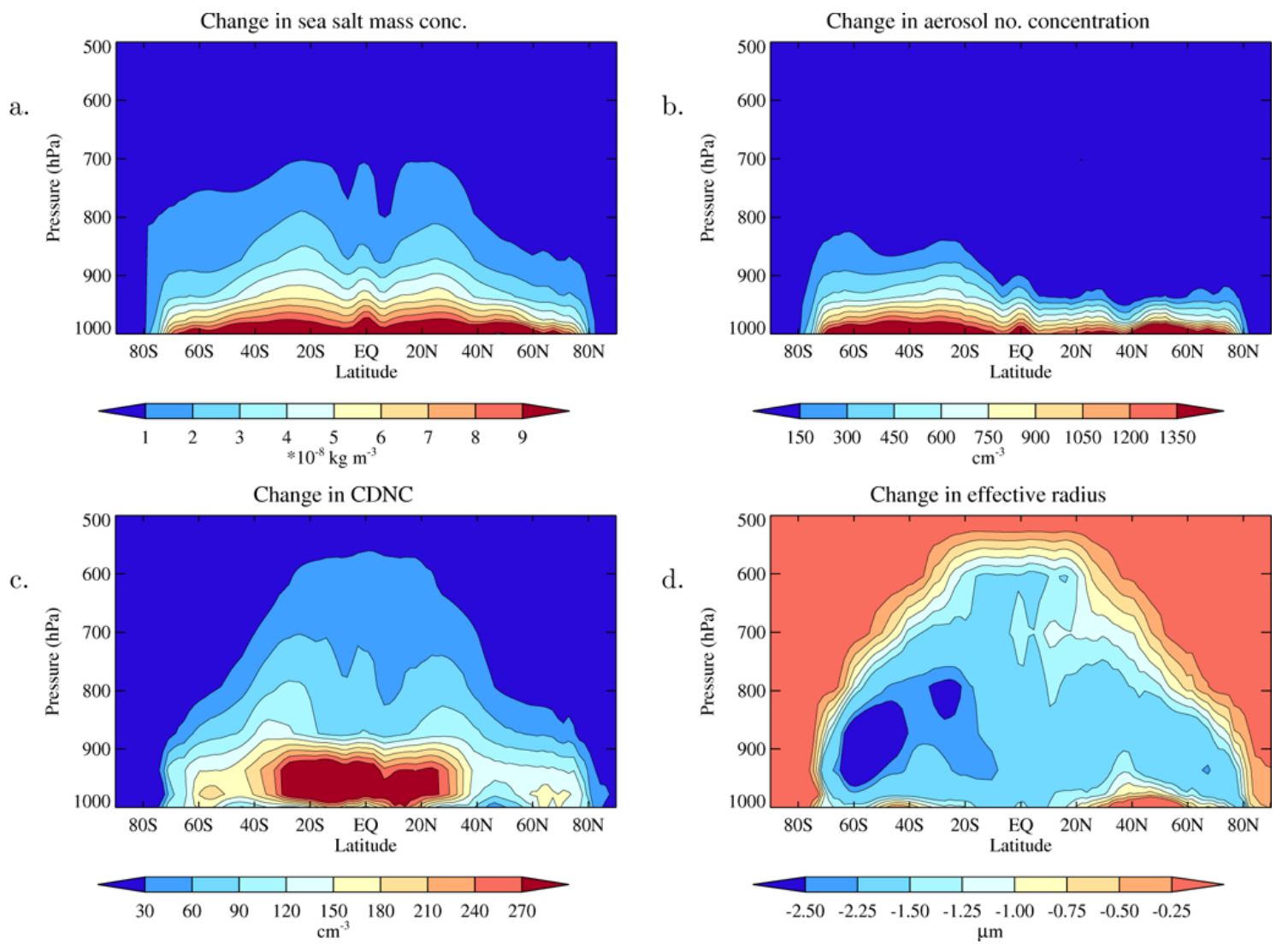

Fig. 8. Zonally averaged changes in (NorESM): (a) sea salt mass concentration $\left(\mathrm{kg} \mathrm{m}^{-3}\right)$, (b) aerosol number concentration $\left(\mathrm{cm}^{-3}\right)$, $(\mathbf{c}) \mathrm{cloud}^{-}$ droplet number concentration $\left(\mathrm{cm}^{-3}\right)$, and $(\mathbf{d})$ effective cloud droplet radius $(\mu \mathrm{m})$. All annual means.

emissions of sea salt with a modal radius of $0.13 \mu \mathrm{m}$ is $-4.8 \mathrm{~W} \mathrm{~m}^{-2}$.

- The effectiveness of cloud seeding is inhibited by: (i) an increased competition effect resulting from increased sea salt concentrations manifests itself through a reduction in the maximum supersaturation, and (ii) condensation of gaseous $\mathrm{H}_{2} \mathrm{SO}_{4}$ on the injected particles rather than nucleation of gaseous sulphuric acid reduces the lifetime and the concentration of particulate $\mathrm{SO}_{4}$.

This study has not focused on possible side effects of cloud seeding, but our results show that adding too small sea salt particles may lead to a decrease in the reflection of solar radiation which is the opposite of what is desired. A global study of the significance of the size of the injected sea salt particles is presented in an upcoming paper. Future studies in this field should involve multidecadal simulations of increased sea salt emissions in different regions to study the climate response to spatially limited cooling of the ocean surface. The cloudweighted susceptibility function presented here may serve as a tool for finding suitable seeding locations in such simulations.
Acknowledgements. The authors are thankful to Johannes Quaas for providing the data set of cloud droplet number concentration retrieved from MODIS and to Ralf Bennartz and the IMPLICC consortium for helpful discussions. We are also thankful to Mats Bentsen for his contribution on the MICOM ocean model component and to Yi Ming for his comment on the time resolution of model output. This study was partly funded by the European Commission's 7th Framework program through the IMPLICC project (Grant No. FP7-ENV-2008-1-226567), and the Norwegian Research Council's Programme for supercomputing (NOTUR) through a grant for computing time.

Edited by: H. Tost

\section{References}

Abdul-Razzak, H. and Ghan, S. J.: A parameterization of aerosol activation 2. Multiple aerosol types, J. Geophys. Res., 105, 6837-6844, 2000.

Assmann, K. M., Bentsen, M., Segschneider, J., and Heinze, C.: An isopycnic ocean carbon cycle model, Geosci. Model Dev., 3, 143-167, doi:10.5194/gmd-3-143-2010, 2010.

Bleck, R. and Smith, L. T.: A Wind-Driven Isopycnic Coordinate Model of the North and Equatorial Atlantic Ocean. 1. Model 
Development and Supporting Experiments, J. Geophys. Res., 95, 3273-3285, 1990.

Bleck, R., Rooth, C., Hu, D., and Smith, L. T.: Salinity-driven Thermocline Transients in a Wind- and Thermohaline-forced Isopycnic Coordinate Model of the North Atlantic, J. Phys. Oceanogr., 22, 1486-1505, 1992.

Bower, K., Choularton, T., Latham, J., Sahraei, J., and Salter, S.: Computational assessment of a proposed technique for global warming mitigation via albedo-enhancement of marine stratocumulus clouds, Atmos. Res., 82, 328-336, doi:10.1016/j.atmosres.2005.11.013, 2006.

Bréon, F.-M. and Doutriaux-Boucher, M.: A comparison of cloud droplet radii measured from space, IEEE. T. Geosci. Remote Sens., 43, 1796-1805, doi:10.1109/TGRS.2005.852838, 2005.

Crutzen, P. J.: Albedo enhancement by stratospheric sulfur injections: a contribution to resolve a policy dilemma?, Climatic Change, 77, 211-220, doi:10.1007/s10584-006-9101-y, 2006.

Ghan, S., Guzman, G., and Abdul-Razzak, H.: Competition between sea salt and sulfate particles as cloud condensation nuclei, J. Atmos. Sci., 55, 3340-3347, 1998.

Hobbs, P. V.: Aerosol-cloud-climate interactions, Academic Press Inc., 1993.

Hoose, C., Kristjánsson, J. E., Iversen, T., Kirkevåg, A., Seland, Ø., and Gettelman, A.: Constraining cloud droplet number concentration in GCMs suppresses the aerosol indirect effect, Geophys. Res. Lett., 36, L12807, doi:10.1029/2009GL038568, 2009.

Hoose, C., Kristjánsson, J. E., Arabas, S., Boers, R., Pawlowska, H., Puygrenier, V., Siebert, H., and Thouron, O.: Parametrization of in-cloud vertical velocities for cloud droplet activation in coarse-grid models: Analyses of observations and cloud resolving model results, no. 6.4 in the 13th AMS Conference on Cloud Physics, AMS, 2010.

Jones, A., Haywood, J., and Boucher, O.: Climate impacts of geoengineering marine stratocumulus clouds, J. Geophys. Res., 114, D10106, doi:10.1029/2008JD011450, 2009.

Koch, D., Schulz, M., Kinne, S., McNaughton, C., Spackman, J. R., Balkanski, Y., Bauer, S., Berntsen, T., Bond, T. C., Boucher, O., Chin, M., Clarke, A., De Luca, N., Dentener, F., Diehl, T., Dubovik, O., Easter, R., Fahey, D. W., Feichter, J., Fillmore, D., Freitag, S., Ghan, S., Ginoux, P., Gong, S., Horowitz, L., Iversen, T., Kirkevåg, A., Klimont, Z., Kondo, Y., Krol, M., Liu, X., Miller, R., Montanaro, V., Moteki, N., Myhre, G., Penner, J. E., Perlwitz, J., Pitari, G., Reddy, S., Sahu, L., Sakamoto, H., Schuster, G., Schwarz, J. P., Seland, Ø., Stier, P., Takegawa, N., Takemura, T., Textor, C., van Aardenne, J. A., and Zhao, Y.: Evaluation of black carbon estimations in global aerosol models, Atmos. Chem. Phys., 9, 9001-9026, doi:10.5194/acp-9-9001-2009, 2009.

Korhonen, H., Carslaw, K. S., and Romakkaniemi, S.: Enhancement of marine cloud albedo via controlled sea spray injections: a global model study of the influence of emission rates, microphysics and transport, Atmos. Chem. Phys., 10, 4133-4143, doi:10.5194/acp-10-4133-2010, 2010

Kristjánsson, J. E.: Studies of the aerosol indirect effect from sulfate and black carbon aerosols, J. Geophys. Res., 107, 4246, doi:10.1029/2001JD000887, 2002.

Latham, J.: Control of global warming?, Nature, 347, 339-340, 1990.

Latham, J.: Amelioration of global warming by controlled enhance- ment of the albedo and longevity of low-level maritime clouds, Atmos. Sci. Lett., 3, 52-58, doi:10.1006/asle.2002.0048, 2002.

Latham, J., Rasch, P., Chen, C.-C., Kettlers, L., Gadian, A., Gettelmann, A., Morrison, H., Bower, K., and Choularton, T.: Global temperature stabilization via controlled albedo enhancement of low-level maritime clouds, Philos. T. R. Soc., 366, 3969-3987, doi:10.1098/rsta.2008.0137, 2008.

Lenton, T. M. and Vaughan, N. E.: The radiative forcing potential of different climate geoengineering options, Atmos. Chem. Phys., 9, 5539-5561, doi:10.5194/acp-9-5539-2009, 2009.

Liou, K. N.: An introduction to atmospheric radiation, 2nd edn., Academic Press, p. 373, 2002.

Mårtensson, M., Nilsson, D., de Leeuw, G., Cohen, L. H., and Hanson, H.-C.: Laboratory simulations and parameterization of the primary marine aerosol production, J. Geophys. Res., 108, 4297, doi:10.1029/2002JD002263, 2003.

Morrison, H. and Gettelman, A.: A new two-moment bulk stratiform cloud microphysics scheme in the community atmosphere model, version 3 (CAM3), Part I: Description and numerical tests, J. Climate, 21, 3642-3659, doi:10.1175/2008JCLI2105.1, 2008.

Oreopoulos, L. and Platnick, S.: Radiative susceptibility of cloudy atmospheres to droplet number perturbations: 2. global analysis from MODIS, J. Geophys. Res., 113, D14S21, doi:10.1029/2007JD009655, 2008.

Penner, J. E., Quaas, J., Storelvmo, T., Takemura, T., Boucher, O., Guo, H., Kirkevåg, A., Kristjánsson, J. E., and Seland, Ø.: Model intercomparison of indirect aerosol effects, Atmos. Chem. Phys., 6, 3391-3405, doi:10.5194/acp-6-3391-2006, 2006.

Pincus, R., Batstone, C., and Platnick, S. E.: Large-scale cloud properties as observed by ISCCP and MODIS, climate Diagnostics Center, NOAA/ESRL, NASA/GSFC, http://modis-atmos. gsfc.nasa.gov/_ppt/Pincus-MODIS-ISCCP.pdf, 2011.

Platnick, S. and Oreopoulos, L.: Radiative susceptibility of cloudy atmospheres to droplet number perturbations: 1. theoretical analysis and examples from MODIS, J. Geophys. Res., 113, D14S20, doi:10.1029/2007JD009654, 2008.

Platnick, S., King, M. D., Ackerman, S. A., Menzel, W. P., Baum, B. A., Riédi, J. C., and Frey, R. A.: The MODIS cloud products: Algorithms and examples from terra, IEEE T. Geosci. Remote Sens., 41, 459-473, 2003.

Quaas, J., Boucher, O., and Lohmann, U.: Constraining the total aerosol indirect effect in the LMDZ and ECHAM4 GCMs using MODIS satellite data, Atmos. Chem. Phys., 6, 947-955, doi:10.5194/acp-6-947-2006, 2006.

Quaas, J., Ming, Y., Menon, S., Takemura, T., Wang, M., Penner, J. E., Gettelman, A., Lohmann, U., Bellouin, N., Boucher, O., Sayer, A. M., Thomas, G. E., McComiskey, A., Feingold, G., Hoose, C., Kristjánsson, J. E., Liu, X., Balkanski, Y., Donner, L. J., Ginoux, P. A., Stier, P., Grandey, B., Feichter, J., Sednev, I., Bauer, S. E., Koch, D., Grainger, R. G., Kirkevåg, A., Iversen, T., Seland, Ø., Easter, R., Ghan, S. J., Rasch, P. J., Morrison, H., Lamarque, J.-F., Iacono, M. J., Kinne, S., and Schulz, M.: Aerosol indirect effects - general circulation model intercomparison and evaluation with satellite data, Atmos. Chem. Phys., 9, 8697-8717, doi:10.5194/acp-9-8697-2009, 2009.

Rasch, P. and Kristjánsson, J. E.: A comparison of the CCM3 model climate using diagnosed and predicted condensate parameterizations, J. Climate, 11, 1587-1614, 1998. 
Salter, S., Sortino, G., and Latham, J.: Sea-going hardware for the cloud albedo method of reversing global warming, Philos. T. R. Soc., 366, 3989-4006, doi:10.1098/rsta.2008.0136, 2008.

Seland, Ø., Iversen, T., Kirkevåg, A., and Storelvmo, T.: Aerosolclimate interactions in the CAM-Oslo atmospheric GCM and investigation of associated basic shortcomings, Tellus, 60A, 459491, 2008.

Sortino, G.: A data resource for cloud cover simulation, Master's thesis, School of Informatics, University of Edinburgh, 2006.

Storelvmo, T., Kristjánsson, J. E., Ghan, S. J., Kirkevåg, A., Seland, $\varnothing$., and Iversen, T.: Predicting cloud droplet number concentration in Community Atmosphere Model (CAM)-Oslo, J. Geophys. Res., 111, D24208, doi:10.1029/2005JD006300, 2006.

Struthers, H., Ekman, A. M. L., Glantz, P., Iversen, T., Kirkevåg, A., Mårtensson, E. M., Seland, Ø., and Nilsson, E. D.: The effect of sea ice loss on sea salt aerosol concentrations and the radiative balance in the Arctic, Atmos. Chem. Phys., 11, 3459-3477, doi:10.5194/acp-11-3459-2011, 2011.
Twomey, S.: Pollution and the planetary albedo, Atmos. Environ., 8, 1251-1256, 1974.

Twomey, S.: Aerosols, clouds, and radiation, Atmos. Environ., 25, 2435-2442, 1991.

Wang, H., Rasch, P. J., and Feingold, G.: Manipulating marine stratocumulus cloud amount and albedo: a process-modelling study of aerosol-cloud-precipitation interactions in response to injection of cloud condensation nuclei, Atmos. Chem. Phys., 11, 4237-4249, doi:10.5194/acp-11-4237-2011, 2011.

Wigley, T. M. L.: A combined mitigation/geoengineering approach to climate stabilization, Science, 314, 452-454, doi:10.1126/science.1131728, 2006. 